\title{
Two Warehouse Inventory Model with Ramp Type Demand and Partial Backordering for Weibull Distribution Deterioration
}

\author{
Ajay Singh \\ Yadav, PhD \\ Assistant Professor \\ SRM University,NCR \\ Campus,GZB,U.P.
}

\author{
BabitaTyagi \\ Professor \\ Galgotais University \\ Greater Noida,U.P.
}

\author{
Sanjai Sharma \\ Resaerch Scholar \\ Banasthali University \\ Jaipur,Rajsthan
}

\author{
Anupam Swami \\ Assistant Professor \\ Govt.P.G.College \\ Sambhal,U.P.
}

\begin{abstract}
In the recent years, the effect of deterioration of physical goods has drawn much attention of various researchers. The more the deteriorationis, the more order quantity would be. According to such consideration, taking the deterioration rate into account is necessary. Thus in this paper, we develop the two ware-house inventory model with partial backlogging and two parameter weibull distribution deterioration. In the present market scenario the demand of certain items does not remain constant with time and may increase/decrease for a fixed time interval. The objective of this paper is to derive the optimal replenishment policy considering varying demand rate and deterioration that minimize the present worth of total relevant inventory cost per unit of time. In addition to this single ware-house system is also developed and the results have been compared with the help of numerical example.
\end{abstract}

\section{Keywords}

Weibull deterioration distribution, partialbacklogging,ramp type demand

\section{INTRODUCTION}

In general, the demand is to be considered either constant or increasing with time. In traditional models many researchers have considered the demand rate as constant, linear time dependent, stock dependent or exponentially increasing with time and the same trend of considering these type of demand is still continues but it is not always true that the demand occurs in same patterni.e. either constant or increasing with time. The assumption of constant demand rate is usually valid at the mature stage of the life cycle of a product. Several researchers e.g.[1-8] etc. have developed inventory models for items stored in two ware-houses under a variety of modelling assumptions. In these models the demand rate is considered to be constant over a time. However, in practice one would accept demand to vary with time. Donaldson ${ }^{9}$ was the first to consider inventory model with time dependent demand and thereafter many researchers such as Goswami and Chaudhuri ${ }^{10}$, Bhunia and Maiti ${ }^{11,1}$ Banerjee and Agrawal $^{13}$ etc. were considered the time dependent demands for two-warehouse inventory systems.

Most of the above mentioned studies consider time varying demand rate either increasing or decreasing with time. However demand cannot increase/decrease continuously over time. e.g in case fashionable goods, demand initially increases with time if customers are attracted by the quality and price and once product accepted in the market, demand stabilises to a constant rate due to new arrivals of fashionable items. This type of stabilization has been considered in the literature since Ritchie ${ }^{14}$.This type of demand is considered as "Ramp Type". Manyresearchers have been considered this type of demand with combination of other assumptions. $\mathrm{Wu}^{15}$ developed an inventory model withramp type demand rate, Weibulldistribution deterioration and partially backlogged shortages. Giri, Jalan, and Chaudhary ${ }^{16}$ used an exponential ramp type function to represent demand. In all above models ,it was assumed that the time point at which demand become constants occurs before the time when the inventory depletes compeletly.Deng,Lin,and $\mathrm{Chu}^{17}$ considered the case when demand becomes constant after the inventory level becomes zero.Skouri,Konstntras,papachristos,and Ganas ${ }^{18}$ further extended the model of Deng et.al. by considering demand as a general type function. All these models considered ramp type demand function for a single ware house model. SwatiAgrawal\&Snigdha Banarjee ${ }^{19,20}$ developed a two warehouse inventory model with ramp type demand and partially backlogged shortages, one for non-deteriorating items and other with constant deterioration rate in which demand is general ramp type function of time is considered.

Most of the classical inventory models assumed the utility of inventory remains constant during their storage period. But in real life, deterioration does occur during the storage period. The problem of deteriorating inventory has received considerable attention in recent years. Most products such as medicine, blood, fish, alcohol, gasoline, vegetables and radioactive chemicals have finite self-life, and start to deteriorate once they are replenished. Above listed researchers, have taken care of deteriorating items in their models and developed the models accordingly.

In addition with deterioration of inventory, limited storage is also a major practical problem for real situation due to the lack of large storage space at the important market places, forcingretailers to own a small ware-house at important market places, however, in order to take advantage of attractive price discount offered on bulk purchase, or in anticipation of growth in demand with time, it may be profitable for the retailer to order a quantity that exceeds the capacity of his own ware-house. At this situation retailer need extra space to store the bulk purchased items and hence prefer to rent a house for a limited period. In case deteriorating items,specially equipped storage facility is required to reduce the amount of deterioration. The cost of building such a storage facility for a limited period is usually exorbitant. Hence, it may be difficult for retailer to have such storage facility of his own at the retail outlet. To handle this 
situation the requirement of another storage space, providing the requisitefacilities become necessity.

In literature, own ware-house is abbreviated as OW and that of rented ware-house is as RW and generally it is assumed that the rented ware house provides better storage facilities as compared to own ware-house and due to this the rate of deterioration is smaller than OW which results more holding cost at RW, therefore retailer prefer to vacant $\mathrm{RW}$ by supplying demanded items earlier to the customers and then from OW.Due to arising problem of storage facility the concept of two ware-house inventory modelling come into existence. For two ware-house, time dependent demand was considered by some authors, such as [13-18].

For deteriorating items, Swati Agrawal and Snigdha Banerjeedeveloped inventory model with ramp type demand and partially backlogged shortages and they further extended the their own model by allowing deterioration for stored items and providing the option for using one or two storage facilities. In this paper they have considered constant deterioration rate in both ware-houses with demand rate as general ramp- type function of time.

Motivated by above papers, we developed a two ware-house inventory model for demand rate as general ramp-type function of time and two parameter Weibull distribution deterioration rate. If the shape parameter is equal to 1 , then the Weibull distribution is reduced to be constant deterioration rate. Shortages are allowed and partially backordered at constant rate.

\section{ASSUMPTIONS AND NOTATION}

The mathematical model of the two-warehouse inventory problem is based on the following

Assumption and notations.

\subsection{Assumptions}

- Demand rate is ramp type.

- The lead time is zero or negligible and initial inventory level is zero.

- The replenishment rate is infinite.

- Shortages are allowed and partially backordered at constant rate.

- Deterioration rate is time dependent and follows a two parameter Weibull distribution where $\alpha, g>$ 0 denote scale parameter and $\beta, \mathrm{h}>1$ denote the shape parameter.

- The holding cost is constant and higher in RW than OW.

- The deteriorated units cannot be repaired or replaced during the period under review.

- Deterioration occurs as soon as items are received into inventory.

\subsection{Notation}

The following notation is used throughout the paper:Demand rate ( units/unit time ) which is ramp type given as

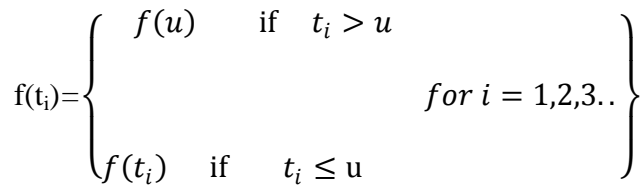

W Capacity of OW

$\alpha \quad$ Scale parameter of the deterioration rate in OW

and

$0<\alpha<1$

$\beta \quad$ Shape parameter of the deterioration rate in OW

and

$\beta>1$.

g Scale parameter of the deterioration rate in RW,

$\begin{array}{ll}\alpha>g & \text { Shape parameter of the deterioration rate in RW } \\ h\end{array}$

and

$\mathrm{h}>1$.

B Fraction of the demand backordered during the

stock

out period

$C_{o} \quad$ Ordering cost per order

$\mathrm{d}_{1} \quad$ Deterioration cost per unit of deteriorated item in

RW $\quad$ Deterioration cost per unit of deteriorated item in

$\mathrm{d}_{2}$

OW

$\mathrm{h}_{\mathrm{w}} \quad$ Holding cost per unit per unit time in OW

$\mathrm{h}_{\mathrm{R}} \quad$ Holding cost per unit per unit time in RW such that $\mathrm{h}_{\mathrm{R}}>\mathrm{h}_{\mathrm{o}}$

$\mathrm{s}_{1} \quad$ Shortage cost per unit per unit time

$\mathrm{s}_{2} \quad$ Shortage cost for lost sales per unit

Q $\quad$ The order quantity in OW

$Q_{R} \quad$ The order quantity in RW

$\mathrm{Q}_{\mathrm{M}} \quad$ Maximum ordered quantity after a complete time period $\mathrm{T}$

$\mathrm{I}_{\mathrm{k}} \quad$ Maximum inventory level in RW $\mathrm{k}=1,2$

$\mathrm{T}_{1} \quad$ Time with positive inventory in RW

$\mathrm{T}_{1}+\mathrm{T}_{2} \quad$ Time with positive inventory in OW

$\mathrm{T}_{3} \quad$ Time when shortage occurs in OW

$\mathrm{T} \quad$ Length of the cycle i.e. $T=T_{1}+T_{2}+T_{3}$

$\mathrm{I}_{\mathrm{ij}}^{\mathrm{t}}\left(t_{i}\right) \quad$ Inventory level for $\Delta_{2}$-system at time

$t i, 0 \leq t_{i} \leq T_{i}, i=1,2,3 \& \mathrm{j}=1,2,3,4,5$.

$I^{S}\left(t_{i}\right) \quad$ Inventory level in RW at time $t_{1}, 0 \leq t_{\mathrm{i}} \leq T_{\mathrm{i}}$

$\Delta_{1} \quad$ Identify single ware-house system

$\Delta_{2} \quad$ Identify two ware-house systems

$\varphi^{t} \quad$ Total cost per cycle for $\Delta_{2}$ system

$\varphi^{S} \quad$ Total cost per cycle for $\Delta_{1}$ system

$\varphi^{t i} \quad$ The present value of the total relevant inventory cost

per unit time for $\Delta_{2}$ system for case $\mathrm{i}=1,2,3$

$\varphi^{s i} \quad$ The present value of the total relevant inventory cost

per unit time for $\Delta_{1}$ systemfor case $\quad \mathrm{i}=1,2$

Rs Initial inventory level for $\Delta_{1}$ system

$\mathrm{R}_{\mathrm{tj}} \quad$ Initial inventory level for $\Delta_{2}$ system

The rate of deterioration is given as follows:

$\mathrm{t}_{\mathrm{i}} \quad$ Time to deterioration, $t_{i}>0$

Instantaneous rate of deterioration in $\mathrm{OW}$

$\theta_{1}\left(\mathrm{t}_{\mathrm{i}}\right)=\alpha \beta t_{i}^{(\beta-1)}$ where $0 \leq \alpha<1 \quad$ and $\beta>1$

Instantaneous rate of deterioration in RW

$\theta_{2}\left(\mathrm{t}_{\mathrm{i}}\right)=g h t_{i}^{(h-1)} \quad$ where $h>1$, 


\section{MATHEMATICAL DEVELOPMENT OF MODEL}

Descriptionfor Two ware-house model $\left(\Delta_{2}-\right.$ system $)$ In the two ware-house Inventory System, cycle length has been divided into three parts i.e. $\mathrm{T}_{1}, \mathrm{~T}_{2}$ and $\mathrm{T}_{3}$. For each replenishment, a portion of the replenished quantity is used to clear backlogged shortages, while the rest enters into the system. Wunits of items are stored in the OW and the rest is kept into the RW. To begin with analysis, it is necessary to compare the value of the constant parameter $u$ with the possible values that the decision variables $T_{1}, T_{2}$ and $T_{3}$ can take on. This results in the following three cases:

Case-1: $0 \leq \mathrm{u} \leq T_{1}$; Case-2: $0 \leq \mathrm{u} \leq T_{2}$; Case-3: $0 \leq \mathrm{u} \leq T_{3}$

Now we discuss each case separately.

\section{Case-1: $0 \leq \mathrm{u} \leq \boldsymbol{T}_{1}$}

In this case, the model parameters are such that the value of $\mathrm{T}_{1}$ will be at least equal to $\mathrm{u}$.The evolution of stock level in the system is depicted in Figure-1.

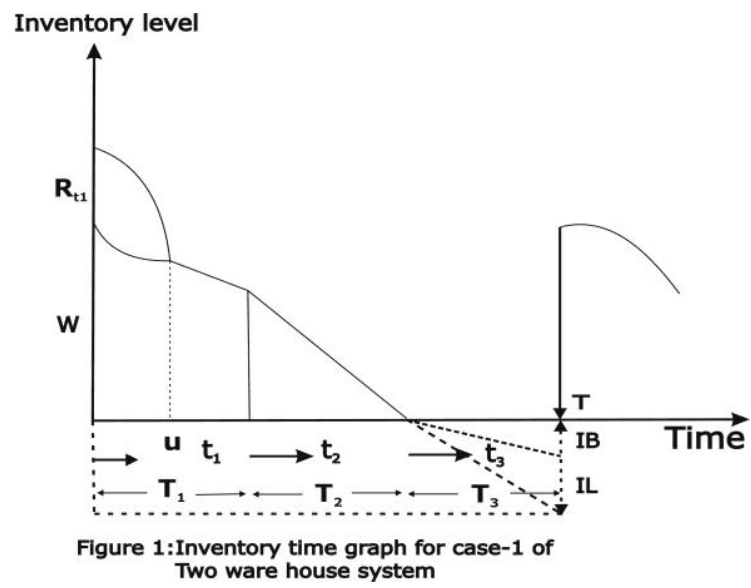

The inventory level at RW decreases due to combined effect of increasing demand and deterioration rate in the time interval $(0 \mathrm{u})$ and due to constant demand and deterioration rate in the time interval $\left(\mathrm{u} \mathrm{T}_{1}\right)$.Hence the inventory level is governed by the following differential equations

$\frac{d \mathrm{I}_{11}^{\mathrm{t}}\left(\mathrm{t}_{1}\right)}{d t_{1}}=-\alpha \beta t_{1}^{\beta-1} \mathrm{I}_{11}^{\mathrm{t}}\left(\mathrm{t}_{1}\right)-\mathrm{f}\left(\mathrm{t}_{1}\right) ; 0 \leq \mathrm{t}_{1} \leq \mathrm{u}$

$\frac{d \mathrm{I}_{12}^{\mathrm{t}}\left(\mathrm{t}_{1}\right)}{d t_{1}}=-\alpha \beta t_{1}^{\beta-1} \mathrm{I}_{12}^{\mathrm{t}}\left(\mathrm{t}_{1}\right)-\mathrm{f}(\mathrm{u}) ; u \leq \mathrm{t}_{1} \leq \mathrm{T}_{1}(1.2)$

With boundary conditions $\mathrm{I}_{11}^{\mathrm{t}}(\mathrm{u})=\mathrm{I}_{12}^{\mathrm{t}}(\mathrm{u})$ and $\mathrm{I}_{12}^{\mathrm{t}}\left(\mathrm{T}_{1}\right)=0$. The solution of $1.1 \& 1.2$ are resp.

$$
\begin{aligned}
\mathrm{I}_{11}^{\mathrm{t}}\left(\mathrm{t}_{1}\right)= & \left(f(u)\left\{\left(\mathrm{T}_{1}-u\right)+\frac{\alpha}{\beta+1}\left(T_{1}^{\beta+1}-u^{\beta+1}\right)\right\}-\right. \\
& \left.\int_{t_{1}}^{u} f(x) e^{\alpha x^{\beta}} d x\right) e^{-\alpha t_{1}^{\beta}} \\
& (1.3)
\end{aligned}
$$

$\mathrm{I}_{12}^{\mathrm{t}}\left(\mathrm{t}_{1}\right)=\left(f(u)\left\{\left(\mathrm{T}_{1}-u\right)+\frac{\alpha}{\beta+1}\left(T_{1}^{\beta+1}-\right.\right.\right.$

$\left.\left.\left.u^{\beta+1}\right)\right\}\right) e^{-\alpha t_{1}^{\beta}}(1.4)$

Since, initially inventory level at RW is $\mathrm{I}_{1}^{\mathrm{t}}(0)=\left(R_{t 1}-w\right)$, we obtain

$$
\begin{aligned}
R_{t 1}= & w+\left(f(u)\left\{\left(\mathrm{T}_{1}-u\right)+\frac{\alpha}{\beta+1}\left(T_{1}^{\beta+1}-u^{\beta+1}\right)\right\}-\right. \\
& \left.\int_{0}^{u} f(x) e^{\alpha x^{\beta}} d x\right)
\end{aligned}
$$

Inventory level at OW during time interval $\left(0 \mathrm{~T}_{1}\right)$ depletes due to deterioration only till inventory reaches zero at RW. The stock at OW depletes due to thecombined effect of constant

demand and deterioration during time interval $\left(\begin{array}{ll}0 & \mathrm{~T}_{2}\end{array}\right)$. Thus differential equations governing this situation are given as

$\frac{d \mathrm{I}_{13}^{\mathrm{t}}\left(\mathrm{t}_{1}\right)}{d t_{1}}=-g h t_{1}^{h-1} \mathrm{I}_{13}^{\mathrm{t}}\left(\mathrm{t}_{1}\right) ; 0 \leq \mathrm{t}_{1} \leq \mathrm{T}_{1}$

$\frac{d \mathrm{I}_{14}^{\mathrm{t}}\left(\mathrm{t}_{2}\right)}{d t_{2}}=-g h t_{1}^{h-1} \mathrm{I}_{14}^{\mathrm{t}}\left(\mathrm{t}_{2}\right)-\mathrm{f}\left(\mathrm{t}_{2}\right) ; \quad 0 \leq \mathrm{t}_{2} \leq \mathrm{T}_{2}$

With boundary conditions $\mathrm{I}_{13}^{\mathrm{t}}(0)=$ wand $\mathrm{I}_{14}^{\mathrm{t}}\left(\mathrm{T}_{2}\right)=0$. The solution of (1.6) \& (1.7) are resp.

$$
\begin{aligned}
\mathrm{I}_{13}^{\mathrm{t}}\left(\mathrm{t}_{1}\right)= & \mathrm{w} e^{-g t_{1}^{h}} \\
& (1.8) \\
\mathrm{I}_{14}^{\mathrm{t}}\left(\mathrm{t}_{2}\right)= & \left(f(u)\left\{\left(\mathrm{T}_{1}-\mathrm{t}_{2}\right)+\frac{g}{h+1}\left(T_{1}^{\beta+1}-t_{2}^{\beta+1}\right)\right\}\right) e^{-g t_{2}^{h}}
\end{aligned}
$$

During the time interval $\left(0 \mathrm{~T}_{3}\right)$ at $\mathrm{T}_{3}=0$ both warehouses are empty, and part of the shortage is backordered at the next replenishment and satisfy the differential equation

$\frac{d \mathrm{I}_{15}^{\mathrm{t}}\left(\mathrm{t}_{3}\right)}{d t_{3}}=-B f(u) ; 0 \leq \mathrm{t}_{3} \leq \mathrm{T}_{3}$

With boundary condition

$\mathrm{I}_{15}^{\mathrm{t}}(0)=0$, the solution of equation (1.10) is given as

$\mathrm{I}_{15}^{\mathrm{t}}\left(\mathrm{t}_{3}\right)=-B f(u) \mathrm{t}_{3}$

(1.11)

The amount of inventory lost sales during the shortages period is

$\mathrm{LS}=(1-\mathrm{B}) \mathrm{f}(\mathrm{u}) \mathrm{T}_{3}$

The total demand during time epoch $\mathrm{T}_{1}$ at $\mathrm{RW}$ is

$\int_{0}^{u} f\left(t_{1}\right) d t_{1}+\int_{u}^{t_{1}} f(u) d t_{1}$

Hence amount of inventory deteriorated during this period is

$\mathrm{D}_{1 R}=R_{t 1}-\int_{0}^{u} f\left(t_{1}\right) d t_{1}-\int_{u}^{t_{1}} f(u) d \mathrm{t}_{1}$

The total demand during time epoch $\mathrm{T}_{1}+\mathrm{T}_{2}$ at $\mathrm{OW}$ is $\int_{0}^{T_{2}} f(u) d t_{2}$

Hence amount of inventory deteriorated during this period is $\mathrm{D}_{1 w}=w-\int_{0}^{T_{2}} f(u) d \mathrm{t}_{2}$

Thus the total present worth inventory cost during the cycle length consist of the following cost elements

- Ordering cost $\mathrm{C}_{o}$

- Inventory holding cost in RW

- Inventory holding cost in OW 
- $\quad$ Shortages cost

- Lost sales cost

- Deterioration cost in RW

- Deterioration cost in OW

Hence the total relevant inventory cost per unit of time during cycle is given by

$$
\begin{aligned}
& \varphi^{t 1}\left(T_{1}, T_{2}, T_{3}\right)= \\
& \frac{1}{T}\left[\begin{array}{c}
\mathrm{C}_{o}+h_{R}\left(\int_{0}^{u} \mathrm{I}_{11}^{\mathrm{t}}\left(\mathrm{t}_{1}\right) d \mathrm{t}_{1}+\int_{0}^{T_{1}} \mathrm{I}_{12}^{\mathrm{t}}\left(\mathrm{t}_{1}\right) d \mathrm{t}_{1}\right)+ \\
h_{w}\left(\int_{0}^{T_{1}} \mathrm{I}_{13}^{\mathrm{t}}\left(\mathrm{t}_{2}\right) d \mathrm{t}_{2}+\int_{0}^{T_{2}} \mathrm{I}_{14}^{\mathrm{t}}\left(\mathrm{t}_{2}\right) d \mathrm{t}_{2}\right)+ \\
s_{1}\left(\int_{0}^{T_{3}}\left(-\mathrm{I}_{5}^{\mathrm{t}}\left(\mathrm{t}_{3}\right)\right) d \mathrm{t}_{3}\right)+s_{2} L S+\mathrm{d}_{1} \mathrm{D}_{1 R}+\mathrm{d}_{2} \mathrm{D}_{1 w}
\end{array}\right](1
\end{aligned}
$$

\section{Case-2: $0 \leq \mathrm{u} \leq \boldsymbol{T}_{2}$}

In this case evolution of inventory level in the system is depicted by Figure-2.

The inventory level at RW decreases due to combined effect of increasing demand and deterioration rate in the time interval $\left(\begin{array}{ll}0 & \mathrm{~T}_{1}\end{array}\right)$.Hence the inventory level is governed by differential equation

$\frac{d \mathrm{I}_{21}^{\mathrm{t}}\left(\mathrm{t}_{1}\right)}{d t_{1}}=-\alpha \beta t_{1}^{\beta-1} \mathrm{I}_{21}^{\mathrm{t}}\left(\mathrm{t}_{1}\right)-\mathrm{f}\left(\mathrm{t}_{1}\right) ; 0 \leq \mathrm{t}_{1} \leq \mathrm{T}_{1}$

With boundary condition $I_{21}^{t}\left(T_{1}\right)=0$. The solution of equation(2.1) is

$\mathrm{I}_{21}^{\mathrm{t}}\left(\mathrm{t}_{1}\right)=\left(\int_{0}^{T_{1}} f(x) e^{\alpha x^{\beta}} d x-\int_{0}^{t_{1}} f(x) e^{\alpha x^{\beta}} d x\right) e^{-\alpha t_{1}^{\beta}}$

$$
\text { (2.2) }
$$

Further, since initially inventory level in RW is $\mathrm{I}_{21}^{\mathrm{t}}(0)=$ $\left(R_{t 2}-W\right)$ andT $_{1}>0$,we obtain

$\left.R_{t 2}=\left(w+\int_{0}^{T_{1}} f(x) e^{\alpha x^{\beta}} d x\right)\right)>W$

Remark-1:If $\mathrm{T}_{1}=0$ the above inequality does not satisfy and the inventory level at RW will be zero. This situation arises when the initial inventory level is less than or equal to W and corresponds to Case-1 of the $\boldsymbol{\Delta}_{\mathbf{1}}$ - $\mathbf{s y s t e m}$, discussed later in section (4.0).

Applying similar arguments to OW over the time interval $(0$ $\left.\mathrm{T}_{1}\right)$ and $\left(0 \mathrm{~T}_{2}\right)$ the following differential equations are obtained

$$
\frac{d \mathrm{I}_{22}^{\mathrm{t}}\left(\mathrm{t}_{1}\right)}{d t_{1}}=-g h t_{1}^{h-1} \mathrm{I}_{22}^{\mathrm{t}}\left(\mathrm{t}_{1}\right) ; \quad 0 \leq \mathrm{t}_{1} \leq \mathrm{T}_{1}
$$

$$
\begin{array}{ll}
\frac{d \mathrm{I}_{23}^{\mathrm{t}}\left(\mathrm{t}_{2}\right)}{d t_{2}}=-g h t_{2}^{h-1} \mathrm{I}_{23}^{\mathrm{t}}\left(\mathrm{t}_{2}\right)-\mathrm{f}\left(\mathrm{t}_{2}\right) ; & 0 \leq \mathrm{t}_{2} \leq \mathrm{u} \\
\frac{d \mathrm{I}_{24}^{\mathrm{t}}\left(\mathrm{t}_{2}\right)}{d t_{2}}=-g h t_{2}^{h-1} \mathrm{I}_{24}^{\mathrm{t}}\left(\mathrm{t}_{2}\right)-\mathrm{f}(\mathrm{u}) ; & u \leq \mathrm{t}_{2} \leq \mathrm{T}_{2}
\end{array}
$$

With boundary conditions $\mathrm{I}_{22}^{\mathrm{t}}(0)=\mathrm{W}, \mathrm{I}_{22}^{\mathrm{t}}\left(\mathrm{T}_{1}\right)=\mathrm{I}_{23}^{\mathrm{t}}(0)$ and $\mathrm{I}_{24}^{\mathrm{t}}\left(\mathrm{T}_{2}\right)=0$ The solution of (2.3), (2.4) \& (2.5 are respectively

$\mathrm{I}_{22}^{\mathrm{t}}\left(\mathrm{t}_{1}\right)=\mathrm{w} e^{-g t_{1}^{h}}$

(2.6)

$$
\begin{aligned}
\mathrm{I}_{23}^{\mathrm{t}}\left(\mathrm{t}_{2}\right)= & \left(W e^{-g T_{1}^{h}}-\int_{0}^{t_{2}} f(x) e^{g x^{h}} d x\right) e^{-g t_{2}^{h}} \\
& (2.7) \\
\mathrm{I}_{24}^{\mathrm{t}}\left(\mathrm{t}_{2}\right)= & \left(f(u)\left\{\left(\mathrm{T}_{2}-\mathrm{t}_{2}\right)+\frac{g}{h+1}\left(T_{2}^{\beta+1}-t_{2}^{\beta+1}\right)\right\}\right) e^{-g t_{2}^{h}}
\end{aligned}
$$

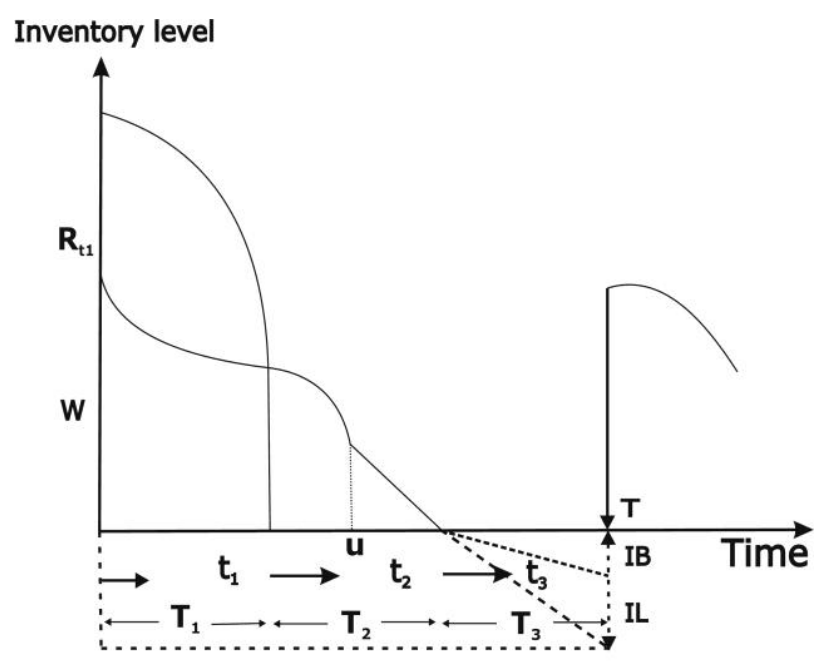

Figure- 2:Inventory time graph for case-2 of Two ware house system

Further, during the time interval $\left(\begin{array}{lll}0 & \mathrm{~T}_{3}\end{array}\right)$ at $\mathrm{T}_{3}=0$ both warehouses are empty, and part of the shortage is backordered at the next replenishment and is same as equation (1.10) of case-1, i.e.

$\mathrm{I}_{15}^{\mathrm{t}}\left(\mathrm{t}_{3}\right)=-B f(u) \mathrm{t}_{3}$

The amount of inventory lost sales during the shortages period is

$\mathrm{LS}=(1-\mathrm{B}) \mathrm{f}(\mathrm{u}) \mathrm{T}_{3}$

The total demand during time epoch $\mathrm{T}_{1}$ at $\mathrm{RW}$ is $\int_{0}^{T_{1}} f\left(t_{1}\right) d t_{1}$ and therefore the amount of deteriorated inventory at RW is

$\mathrm{D}_{2 R}=R_{t 2}-\int_{0}^{T_{1}} f\left(t_{1}\right) d t_{1}$

The total demand during time epoch $\mathrm{T}_{1}+\mathrm{T}_{2}$ at $\mathrm{OW}$ is $\int_{0}^{u} f\left(t_{2}\right) d t_{2}-\int_{u}^{T_{2}} f(u) d t_{2}$

And amount of inventory deteriorated during the period $\mathrm{T}_{1}+$ $\mathrm{T}_{2}$ at $\mathrm{OW}$ is

$\mathrm{D}_{2 w}=w-\int_{0}^{u} f\left(t_{2}\right) d t_{2}-\int_{u}^{T_{2}} f(u) d \mathrm{t}_{2}$

Hence in this case the total cost per unit of time during cycle is given by

$$
\begin{array}{ccc}
\varphi^{t 2}\left(T_{1}, T_{2}, T_{3}\right)= & \frac{1}{T}\left[\mathrm{C}_{o}+h_{R}\left(\int_{0}^{T_{1}} \mathrm{I}_{21}^{\mathrm{t}}\left(\mathrm{t}_{1}\right) d \mathrm{t}_{1}\right)+\right. \\
& h_{w}\left(\int_{0}^{T_{1}} \mathrm{I}_{22}^{\mathrm{t}}\left(\mathrm{t}_{2}\right) d \mathrm{t}_{2}+\int_{0}^{u} \mathrm{I}_{23}^{\mathrm{t}}\left(\mathrm{t}_{2}\right) d \mathrm{t}_{2}+\right. \\
& \left.\int_{u}^{T_{2}} \mathrm{I}_{24}^{\mathrm{t}}\left(\mathrm{t}_{2}\right) d \mathrm{t}_{2}\right)+ \\
s_{1}\left(\int_{0}^{T_{3}}-\mathrm{I}_{5}^{\mathrm{t}}\left(\mathrm{t}_{3}\right) d \mathrm{t}_{3}\right)+ & s_{2} L S+ \\
\left.\mathrm{d}_{1} \mathrm{D}_{2 R}+\mathrm{d}_{2} \mathrm{D}_{2 w}\right] &
\end{array}
$$

Case-3: $0 \leq \mathrm{u} \leq \boldsymbol{T}_{3}$ 
In this case evolution of inventory level in the system is depicted by Figure-3.

The inventory level both at RW and OW become zero before the demand is stabilizes, Thus inventory level at both the ware-houses decreases due to combined effect of increasing demand and deterioration rate in the time interval $(0$ $\mathrm{T}_{1}$ ).Hence the inventory level governed by differential equation is given as

$\frac{d \mathrm{I}_{31}^{\mathrm{t}}\left(\mathrm{t}_{1}\right)}{d t_{1}}=-\alpha \beta t_{1}^{\beta-1} \mathrm{I}_{31}^{\mathrm{t}}\left(\mathrm{t}_{1}\right)-\mathrm{f}\left(\mathrm{t}_{1}\right) ; \quad 0 \leq \mathrm{t}_{1} \leq \mathrm{T}_{1}$

With boundary condition $\mathrm{I}_{21}^{\mathrm{t}}\left(\mathrm{T}_{1}\right)=0$. The solution of $(3.1)$ is

$\mathrm{I}_{31}^{\mathrm{t}}\left(\mathrm{t}_{1}\right)=\left(\int_{0}^{T_{1}} f(x) e^{\alpha x^{\beta}} d x-\int_{0}^{t_{1}} f(x) e^{\alpha x^{\beta}} d x\right) e^{-\alpha t_{1}^{\beta}}$

Further, since initially, inventory level in RW is $\mathrm{I}_{31}^{\mathrm{t}}(0)=\left(R_{t 3}-W\right)$ and $\mathrm{T}_{1}>0$, therefore we obtain

$\left.R_{t 3}=\left(w+\int_{0}^{T_{1}} f(x) e^{\alpha x^{\beta}} d x\right)\right)>W$

Remark-2:If $\mathrm{T}_{1}=0$ the above inequality does not satisfy and the inventory level at RW will be zero. This situation arises when the initial inventory level is less than or equal to $\mathrm{W}$ and corresponds to Case-2 of the $\boldsymbol{\Delta}_{\mathbf{1}}$ - system, discussed later in section (4.0).

At OW, inventory level decreases due to deterioration over time interval $\left(0 \mathrm{~T}_{1}\right)$ and over $\left(0 \mathrm{~T}_{2}\right)$ due to the increasing demand rate and deterioration. Thus the following differential equations are obtained related to this situation

$\frac{d \mathrm{I}_{32}^{\mathrm{t}}\left(\mathrm{t}_{1}\right)}{d t_{1}}=-g h t_{1}^{h-1} \mathrm{I}_{32}^{\mathrm{t}}\left(\mathrm{t}_{1}\right) ; 0 \leq \mathrm{t}_{1} \leq \mathrm{T}_{1}$

$\frac{d \mathrm{I}_{33}^{\mathrm{t}}\left(\mathrm{t}_{2}\right)}{d \mathrm{t}_{2}}=-g h t_{2}^{h-1} \mathrm{I}_{33}^{\mathrm{t}}\left(\mathrm{t}_{2}\right)-\mathrm{f}\left(\mathrm{t}_{2}\right) ; 0 \leq \mathrm{t}_{2} \leq \mathrm{T}_{2}(3.3)$

With boundary conditions $\mathrm{I}_{32}^{\mathrm{t}}(0)=\mathrm{W}$, and $\mathrm{I}_{33}^{\mathrm{t}}\left(\mathrm{T}_{2}\right)=0$, the solution of (3.2) \& (3.3) are respectively

$\mathrm{I}_{32}^{\mathrm{t}}\left(\mathrm{t}_{1}\right)=\mathrm{w} e^{-g t_{1}^{h}}$

$\mathrm{I}_{33}^{\mathrm{t}}\left(\mathrm{t}_{2}\right)=\left(\int_{0}^{T_{1}} f(x) e^{g x^{h}} d x-\int_{0}^{t_{1}} f(x) e^{g x^{h}} d x\right) e^{-g t_{1}^{h}}$

(3.5)

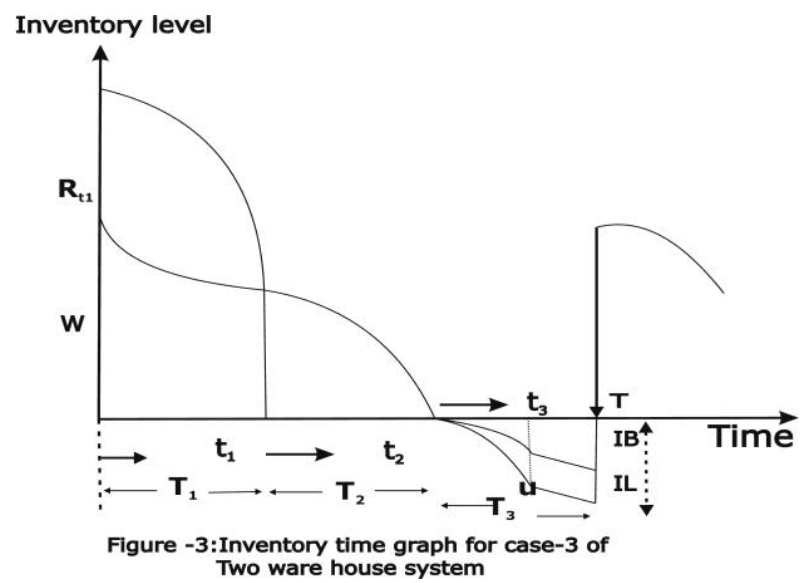

Further, during the time interval $\left(\begin{array}{ll}0 & \mathrm{~T}_{3}\end{array}\right)$ at $\mathrm{T}_{3}=0$ both warehouses are empty, and part of the shortage is backordered at the next replenishment and differential equations governing this situation are given as.

$\frac{d \mathrm{I}_{34}^{\mathrm{t}}\left(\mathrm{t}_{3}\right)}{d t_{3}}=-B f\left(\mathrm{t}_{3}\right) ; \quad 0 \leq \mathrm{t}_{3} \leq \mathrm{u}$

$\frac{d \mathrm{I}_{35}^{\mathrm{t}}\left(\mathrm{t}_{3}\right)}{d t_{3}}=-B f(\mathrm{u}) ; \quad 0 \leq \mathrm{t}_{3} \leq \mathrm{T}_{2}$

With boundary conditions $\mathrm{I}_{34}^{\mathrm{t}}(0)=0$, and $\mathrm{I}_{34}^{\mathrm{t}}(\mathrm{u})=$ $\mathrm{I}_{35}^{\mathrm{t}}(\mathrm{u})$, the solution of (3.6) \& (3.7) are respectively

$\mathrm{I}_{34}^{\mathrm{t}}\left(\mathrm{t}_{3}\right)=-B \int_{0}^{t_{3}} f(x) d x$

$\mathrm{I}_{35}^{\mathrm{t}}\left(\mathrm{t}_{3}\right)=-B\left(f(\mathrm{u})\left(\mathrm{t}_{3}-u\right)+\int_{0}^{u} f(x) d x\right)$

The amount of inventory lost sales during the shortages period is

$\mathrm{LS}=(1-\mathrm{B})\left(\int_{0}^{u} f\left(\mathrm{t}_{3}\right) d \mathrm{t}_{3}+\int_{0}^{\mathrm{T}_{3}} f\left(\mathrm{t}_{3}\right) d \mathrm{t}_{3}\right)$

The total demand during time epoch $\mathrm{T}_{1}$ at RW is $\int_{0}^{T_{1}} f\left(t_{1}\right) d t_{1}$ and therefore

The amount of deteriorated inventory at RW is

$\mathrm{D}_{3 R}=R_{t 3}-\int_{0}^{T_{1}} f\left(t_{1}\right) d t_{1}$

The total demand during time epoch $\mathrm{T}_{1}+\mathrm{T}_{2}$ at $\mathrm{OW}$ is $\int_{u}^{T_{2}} f\left(\mathrm{t}_{2}\right) d \mathrm{t}_{2}$ and therefore

Amount of inventory deteriorated during the period $\mathrm{T}_{1}+\mathrm{T}_{2}$ at $\mathrm{OW}$ is

$\mathrm{D}_{3 w}=W-\int_{u}^{T_{2}} f\left(\mathrm{t}_{2}\right) d \mathrm{t}_{2}$

Hence in this case the total cost per unit of time during cycle is given by

$\varphi^{t 3}\left(T_{1}, T_{2}, T_{3}\right)=\frac{1}{T}\left[\mathrm{C}_{o}+h_{R}\left(\int_{0}^{T_{1}} \mathrm{I}_{31}^{\mathrm{t}}\left(\mathrm{t}_{1}\right) d \mathrm{t}_{1}\right)+\right.$

$h_{w}\left(\int_{0}^{T_{1}} \mathrm{I}_{32}^{\mathrm{t}}\left(\mathrm{t}_{2}\right) d \mathrm{t}_{2}+\int_{0}^{T_{2}} \mathrm{I}_{33}^{\mathrm{t}}\left(\mathrm{t}_{2}\right) d \mathrm{t}_{2}\right)+$

$s_{1}\left(\int_{0}^{u}-\mathrm{I}_{34}^{\mathrm{t}}\left(\mathrm{t}_{3}\right) d \mathrm{t}_{3}+\int_{u}^{T_{3}}-\mathrm{I}_{35}^{\mathrm{t}}\left(\mathrm{t}_{3}\right) d \mathrm{t}_{3}\right)+s_{2} L S+\mathrm{d}_{1} \mathrm{D}_{3 R}+$

$\left.\mathrm{d}_{2} \mathrm{D}_{3 w}\right]$

Combining (1.12), (2.10) \& (3.10), the cost function $\varphi^{t}\left(T_{1}, T_{2}, T_{3}\right)$ of the problem results in the following threebranch function corresponding to the three cases.

$\varphi^{t}\left(T_{1}, T_{2}, T_{3}\right)=\left\{\begin{array}{cc}\varphi^{t 1}\left(T_{1}, T_{2}, T_{3}\right) & 0 \leq \mathrm{u} \leq \mathrm{T}_{1} \\ \varphi^{t 2}\left(T_{1}, T_{2}, T_{3}\right) & 0 \leq \mathrm{u} \leq \mathrm{T}_{2} \\ \varphi^{t 3}\left(T_{1}, T_{2}, T_{3}\right) & 0 \leq \mathrm{u} \leq \mathrm{T}_{3}\end{array}\right.$

Optimality condition for $\Delta_{2}-$ system

The optimal problem can be formulated as

Minimize: $\varphi^{t}\left(T_{1}, T_{2}, T_{3}\right)$

Subject to: $\left(T_{1}>0, T_{2}>0, T_{3}>0\right)$

To find the optimal solution of the equation the following condition must be satisfied 
$\frac{\left.\partial \varphi^{t}\left(T_{1}, T_{2}, T_{3}\right)\right)}{\partial T_{1}}=0 ; \quad \frac{\partial \varphi^{t}\left(T_{1}, T_{2}, T_{3}\right)}{\partial T_{2}}=0 ; \quad \frac{\partial \varphi^{t}\left(T_{1}, T_{2}, T_{3}\right)}{\partial T_{3}}=0$

(3.12)

Solving equation (3.12) respectively for $\mathrm{T}_{1}, \mathrm{~T}_{2}, \mathrm{~T}_{3}$, we can obtain $T_{1}^{*}, T_{2}^{*}, T_{3}^{*}$, and $\mathrm{T}$ and with these optimal values we can find the total minimum inventory cost from equation (3.11) for three branches separately.

\section{DESCRIPTION FOR SINGLE WARE-HOUSE ( $\Delta_{1}$-SYSTEM)}

In this system, we consider the two cases one with unlimited capacity of a ware-house i.e. a rented ware-house (RW) system and other one with limited capacity i.e. own warehouse (OW) system, separately and shall briefly present the analysis. As stated in remarks 1 and 2, this may be treated as a particular case of $\boldsymbol{\Delta}_{\mathbf{2}}$-system by relaxing the condition $\mathrm{T}_{1}>0$

\subsection{RW Case}

At $t_{1}=0$, the amount of inventory ordered enters into the system. Part of it used to fulfil the backlogged shortages of the previous period and $R_{s 1}$ units are stored in RW.The following two subcases arises according to increasing demand period and must be examined:

Subcase-1: $0 \leq \mathrm{u} \leq \mathrm{T}_{1} ;$ Subcase-2: $0 \leq \mathrm{u} \leq \mathrm{T}_{3}$

Now each case will be considered separately.

Subcase-1: $0 \leq \mathrm{u} \leq \mathrm{T}_{1}$

In this case inventory level depleted due to combined effect of both increasing demand and deterioration over time period $\left(\begin{array}{ll}0 & \mathrm{u}\end{array}\right)$ and due to constant demand over $\left(0 \mathrm{~T}_{1}\right)$. At the point of time $\mathrm{T}_{1}$, inventory vanishes and shortages partially backlogged accumulate till time $\mathrm{T}_{3}$. The situation is depicted by Figure-4.

The total cost function per unit of time is found to be

$$
\begin{aligned}
& \varphi^{s 1}\left(T_{1}, T_{3}\right)= \\
& \frac{1}{T}\left[\mathrm{C}_{o}+h_{R}\left(\int_{0}^{u} \mathrm{I}_{11}^{\mathrm{t}}\left(\mathrm{t}_{1}\right) d \mathrm{t}_{1}+\int_{u}^{T_{1}} \mathrm{I}_{12}^{\mathrm{t}}\left(\mathrm{t}_{1}\right) d \mathrm{t}_{1}\right)+\right. \\
& \left.s_{1}\left(\int_{0}^{T_{3}}-\mathrm{I}_{3}^{\mathrm{t}}\left(\mathrm{t}_{3}\right) d \mathrm{t}_{3}\right)+s_{2} L S+\mathrm{d}_{1} \mathrm{D}_{1 R}\right]
\end{aligned}
$$

(4.1)

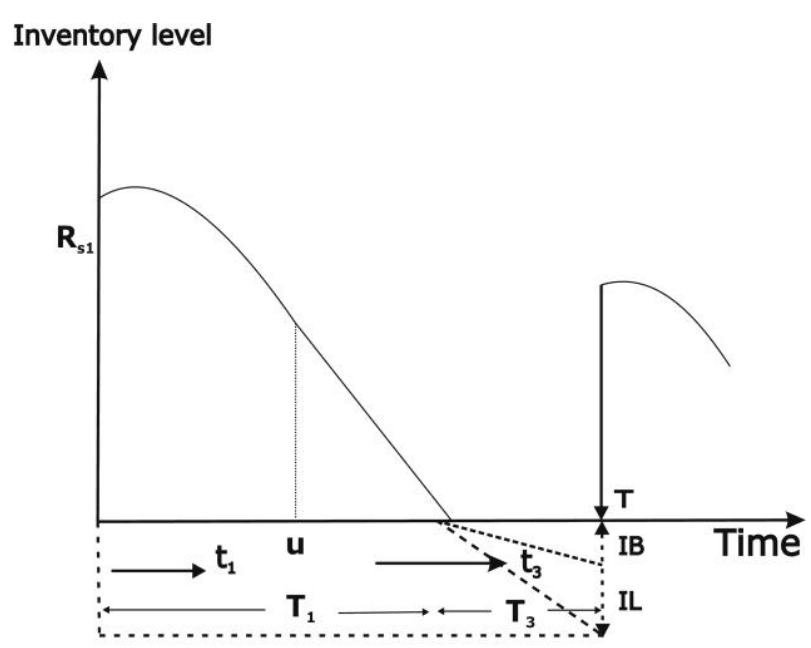

Figure 4:Inventory- time graph for case-1 of single warehouse system

The level $R_{S 1}$ found to be

$$
\begin{gathered}
R_{s 1}=\left(f(u)\left\{\left(\mathrm{T}_{1}-u\right)+\frac{\alpha}{\beta+1}\left(T_{1}^{\beta+1}-u^{\beta+1}\right)\right\}\right. \\
\left.-\int_{0}^{u} f(x) e^{\alpha x^{\beta}} d x\right)
\end{gathered}
$$

Case2: $0 \leq \mathbf{u} \leq \mathbf{T}_{3}$

In this case inventory level depleted due to increasing demand and deterioration over time period $\left(0 \mathrm{~T}_{1}\right)$. At the point of time $\mathrm{T}_{1}$, inventory vanishes and shortages occur due to increasing demand in the period $(0 \mathrm{u})$ and due to constant demand over time period $\left(0 \mathrm{~T}_{3}\right)$ and partially backlogged accumulate till time $\mathrm{T}_{3}$. The situation is presented by Figure-5.

The total cost function per unit of time is found to be

$$
\begin{array}{ll}
\varphi^{s 2}\left(T_{1}, T_{3}\right)= & \frac{1}{T}\left[\mathrm{C}_{o}+h_{R}\left(\int_{0}^{T_{1}} \mathrm{I}_{21}^{\mathrm{t}}\left(\mathrm{t}_{1}\right) d \mathrm{t}_{1}\right)+\right. \\
\left.\int_{u}^{T_{3}}-\mathrm{I}_{23}^{\mathrm{t}}\left(\mathrm{t}_{3}\right) d \mathrm{t}_{3}\right)+ & S_{0}^{u}-\mathrm{I}_{22}^{\mathrm{t}}\left(\mathrm{t}_{3}\right) d \mathrm{t}_{3}+ \\
S_{2} L S+\mathrm{d}
\end{array}
$$

The level $R_{s 2}$ found to be

$R_{s 2}=\left(\int_{0}^{T_{1}} f(x) e^{\alpha x^{\beta}} d x\right)$

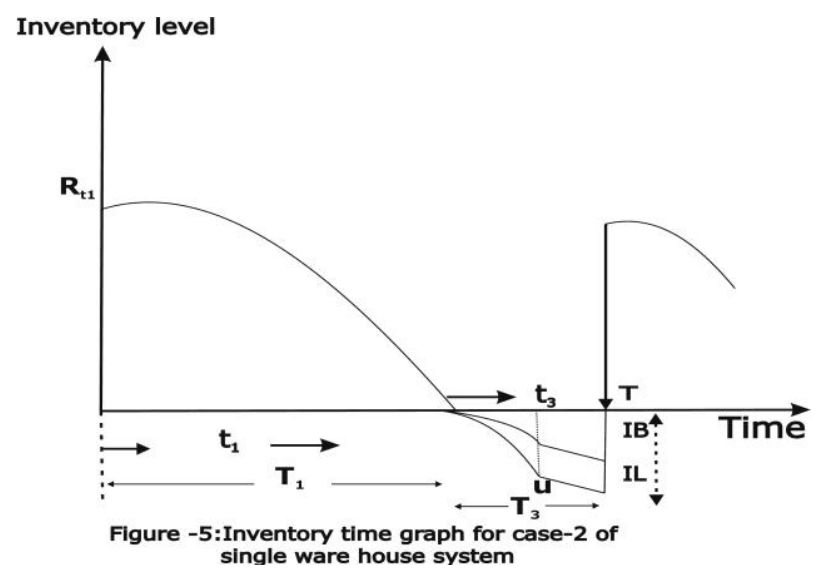

Thus cost function per unit of time for the cycle for these two subcases shall be given by two branch function combining equations (4.1) \& (4.2) as follows

$\varphi^{s}\left(T_{1}, T_{3}\right)=\left\{\begin{array}{cc}\varphi^{s 1}\left(T_{1}, T_{3}\right) & 0 \leq \mathrm{u} \leq \mathrm{T}_{1} \\ \varphi^{s 2}\left(T_{1}, T_{3}\right) & 0 \leq \mathrm{u} \leq \mathrm{T}_{3}\end{array}\right.$

Optimality condition forRW Case ( $\Delta_{\mathbf{1}}$-system) The optimal problem for this system can be formulated as Minimize: $\varphi^{S}\left(T_{1}, T_{3}\right)$

Subject to: $\left(T_{1}>0, T_{3}>0\right)$

To find the optimal solution of the equation the following condition must be satisfied

$\frac{\partial \varphi^{s}\left(T_{1}, T_{3}\right)}{\partial T_{1}}=0 ; \frac{\partial \varphi^{s}\left(T_{1}, T_{3}\right)}{\partial T_{3}}=0 ;$

\subsection{OW Case}

At $\mathrm{t}_{1}=0$, the amount of inventory ordered, enters into the system. Part of it used to fulfil the backlogged shortages of the previous period and a maximum of $\mathrm{W}$ units are stored in OW. The following two sub cases arises according to increasing demand period and must be examined:

Subcase-1: $0 \leq \mathrm{u} \leq \mathrm{T}_{1} ;$ Subcase-2: $0 \leq \mathrm{u} \leq \mathrm{T}_{3}$

Now each case will be considered separately.

Subcase-1: $0 \leq \mathrm{u} \leq \mathrm{T}_{1}$ 
In this case inventory level depleted due to combined effect of both increasing demand and deterioration over time period $(0 \mathrm{u})$ and due to constant demand over $\left(0 \mathrm{~T}_{1}\right)$. At the point of time $\mathrm{T}_{1}$, inventory vanishes and shortages partially backlogged accumulate till time $\mathrm{T}_{3}$. The situation is presented by Figure-6.

The total cost function per unit of time is found to be

$$
\begin{aligned}
& \varphi^{s 1}\left(T_{1}, T_{3}\right)= \\
& \frac{1}{T}\left[\mathrm{C}_{o}+h_{W}\left(\int_{0}^{u} \mathrm{I}_{11}^{\mathrm{t}}\left(\mathrm{t}_{1}\right) d \mathrm{t}_{1}+\int_{u}^{T_{1}} \mathrm{I}_{12}^{\mathrm{t}}\left(\mathrm{t}_{1}\right) d \mathrm{t}_{1}\right)+\right. \\
& \text { s10T3-I3tt3dt3+s2LS+d 1D } 1 W
\end{aligned}
$$$$
\text { (4.4) }
$$

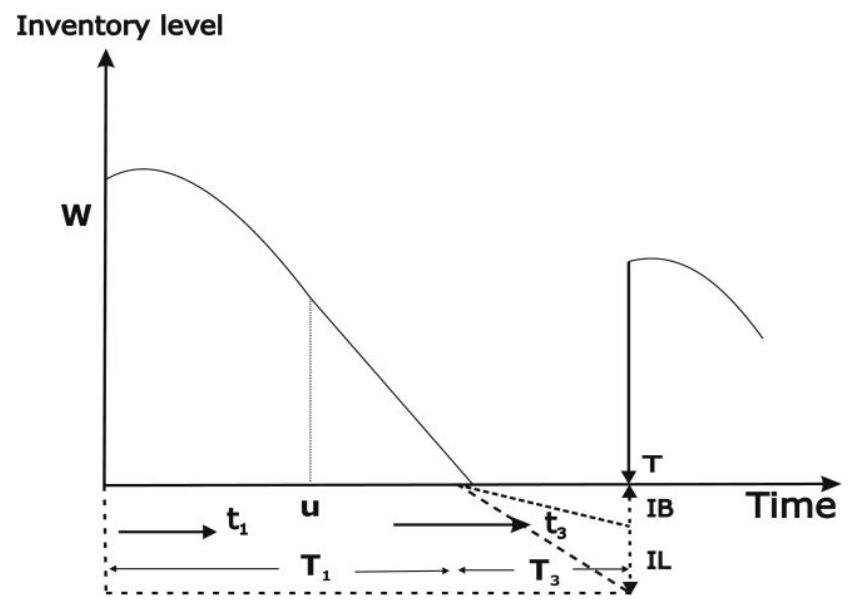

Figure 6:Inventory- time graph for case-1 of single warehouse system

Subcase2: $\mathbf{0} \leq \mathbf{u} \leq \mathbf{T}_{3}$

In this case inventory level depleted due to increasing demand and deterioration over time period $\left(0 \mathrm{~T}_{1}\right)$. At the point of time $\mathrm{T}_{1}$, inventory vanishes and shortages occur due to increasing demand in the period $(0 \mathrm{u})$ and due to constant demand over time period $\left(0 \mathrm{~T}_{3}\right)$ and partially backlogged accumulate till time $\mathrm{T}_{3}$. The situation is presented by Figure-7.

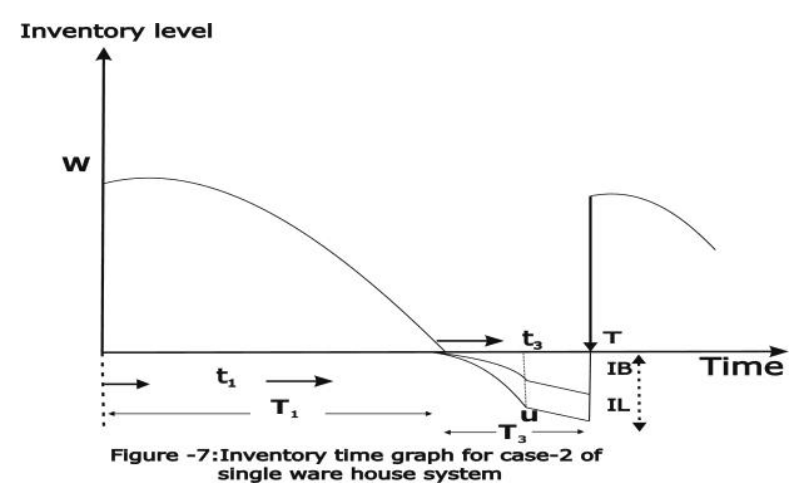

The total cost function per unit of time is found to be

$$
\varphi^{s 2}\left(T_{1}, T_{3}\right)=\quad \begin{gathered}
\frac{1}{T}\left[\mathrm{C}_{o}+h_{W}\left(\int_{0}^{T_{1}} \mathrm{I}_{21}^{\mathrm{t}}\left(\mathrm{t}_{1}\right) d \mathrm{t}_{1}\right)+\right. \\
s 10 u-\mathrm{I} 22 \mathrm{tt} 3 d \mathrm{t} 3+u T 3-\mathrm{I} 23 \mathrm{tt} 3 d \mathrm{t} 3+
\end{gathered}
$$

$s 2 L S+\mathrm{d} 1 \mathrm{D} 2 W$

(4 Thus cost function

per unit of time for the cycle for these two cases shall be given by two branch function combining equations (4.1) \& (4.2) as follows

$\varphi^{s}\left(T_{1}, T_{3}\right)=\left\{\begin{array}{cc}\varphi^{s 1}\left(T_{1}, T_{3}\right) & 0 \leq \mathrm{u} \leq \mathrm{T}_{1} \\ \varphi^{s 2}\left(T_{1}, T_{3}\right) & 0 \leq \mathrm{u} \leq \mathrm{T}_{3}\end{array}\right.$

(4.6)

\section{Optimality condition forOW case ( $\Delta_{1}$ system)}

The optimal problem for this system can be formulated as

$$
\text { Minimize: } \varphi^{S}\left(T_{1}, T_{3}\right)
$$

Subject to: $\left(T_{1}>0, T_{3}>0\right)$

To find the optimal solution of the equation the following condition must be satisfied

$$
\frac{\partial \varphi^{s}\left(T_{1}, T_{3}\right)}{\partial T_{1}}=0 ; \frac{\partial \varphi^{s}\left(T_{1}, T_{3}\right)}{\partial T_{3}}=0
$$

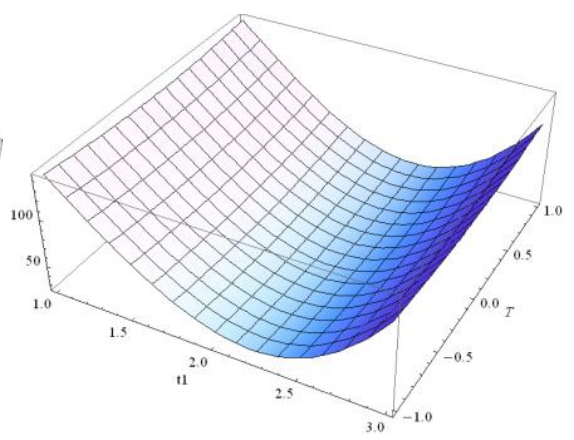

OW-2

RW-1 


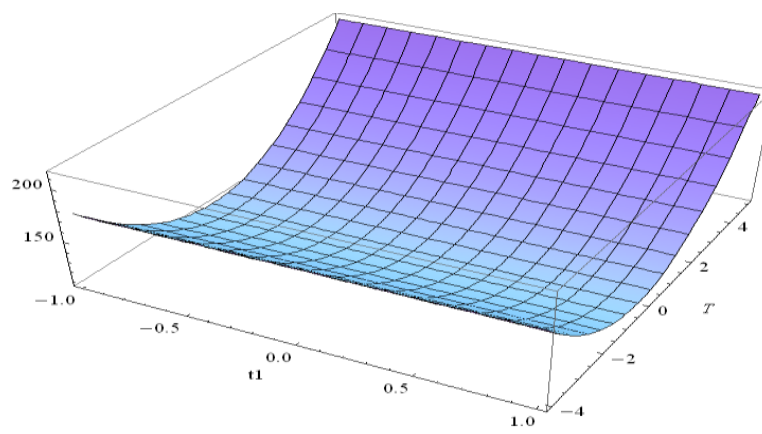

RW-12

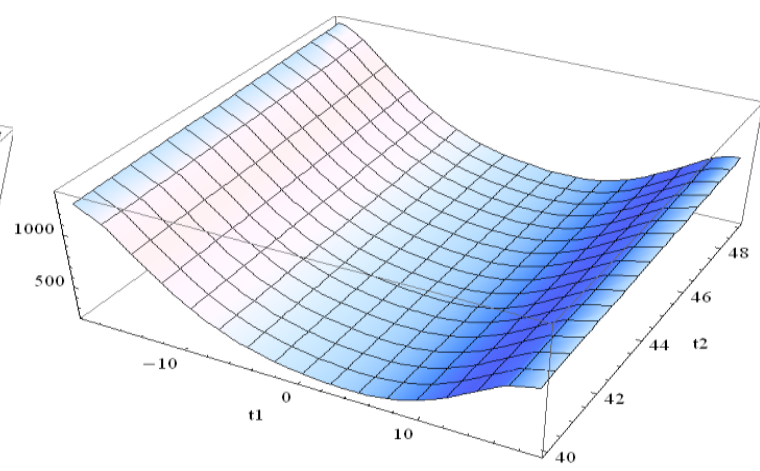

OW-1

Figure-8: Graphical representation of convexity of $\Delta_{1}$ - system

Table-1

$\Delta_{1}$-system

RW OW

\begin{tabular}{ccccccccr} 
Subcase & $T_{1}^{*}$ & $T_{3}^{*}$ & $\mathrm{~T}$ & Total cost & $T_{1}^{*}$ & $T_{3}^{*}$ & $\mathrm{~T}$ & Total cost \\
\hline 1 & 0.5605 & 5.6578 & 6.218 & 172.34 & 18.216 & 48.364 & 66.58 & 864.39 \\
2 & 0.5671 & 4.4464 & 5.013 & 192.99 & 2.2598 & 0.689 & 2.949 & 29.740
\end{tabular}

Table-2

\begin{tabular}{cccccccccccc}
\hline & \multicolumn{9}{c}{$\mathbf{c} \Delta_{\mathbf{1}}$-system } & \multicolumn{3}{c}{ OW } \\
Subcase & $T_{1}^{*}$ & $T_{3}^{*}$ & $\mathrm{~T}$ & $R_{S r}$ & Total cost & $T_{1}^{*}$ & $T_{3}^{*}$ & $\mathrm{~T}$ & $R_{S w}$ & Total cost \\
\hline 1 & 17.0459 & 2.3329 & 19.38 & 2448 & 4328.5 & 17.6866 & 1.3418 & 19.028 & 50 & 1957.94 \\
2 & 1.0064 & 0.2953 & 1.302 & 99 & 525.89 & 2.2215 & 0.0688 & 2.2903 & 50 & 4.0813 \\
\hline
\end{tabular}

\begin{tabular}{lccccc}
\hline & \multicolumn{2}{c}{$\boldsymbol{\Delta}_{2}$-system } & $T^{*}$ & Total cost \\
\hline 1 & $T_{1}^{*}$ & $T_{2}^{*}$ & $T_{3}^{*}$ & 0.1206 & 8.1594 \\
2.0212 & 7.1320 & 0.2392 & 8.2044 & 467.44 \\
3 & 1.0176 & 1.4240 & 0.2775 & 2.5576 & 484.95 \\
\hline
\end{tabular}

Table-3

Sensitivity analysis for the case-1 of two ware-house model with change in the value of one parameter keeping rest unchanged

\begin{tabular}{cccccccccc}
\hline $\begin{array}{c}\text { Initial } \\
\text { value of } \\
\text { parameter }\end{array}$ & $\begin{array}{c}\text { change } \\
\text { value of } \\
\text { parameter }\end{array}$ & $\boldsymbol{T}_{\mathbf{1}}^{*}$ & $\boldsymbol{T}_{\mathbf{2}}^{*}$ & $\boldsymbol{T}_{\mathbf{3}}^{*}$ & $\begin{array}{c}\text { Change in } \\
\text { cycle length } \boldsymbol{T}^{*}\end{array}$ & $\begin{array}{c}\text { \% change in } \\
\text { cycle length }\end{array}$ & $\begin{array}{c}\text { Change in } \\
\text { Total cost }\end{array}$ & $\begin{array}{c}\text { \% change in } \\
\text { total cost }\end{array}$ \\
\hline 30 & 15 & 1.0364 & 6.8895 & 0.3355 & 8.2614 & -1.25009 & 254.00 & -37.66 \\
A & 45 & 1.0108 & 7.0616 & 0.0484 & 8.1208 & 0.473074 & 560.50 & 37.57 \\
4.5 & 2.25 & 1.0332 & 6.9514 & 0.2382 & 8.2228 & -0.77702 & 302.40 & -25.78 \\
b & 6.75 & 1.0098 & 7.0535 & 0.0632 & 8.1265 & 0.403216 & 512.31 & 25.74 \\
500 & 250 & 0.9194 & 7.0582 & 0.0561 & 8.0337 & 1.540554 & 376.54 & -7.58 \\
c & 750 & 1.1133 & 6.9833 & 0.1856 & 8.2822 & -1.50501 & 437.85 & 7.46 \\
4.5 & 2.25 & 1.0333 & 6.9392 & 0.2579 & 8.2304 & -0.87016 & 308.42 & -24.30 \\
u & 6.75 & 1.0098 & 7.0707 & 0.3190 & 8.3995 & -2.94262 & 495.70 & 21.66 \\
3 & 1.5 & 1.8368 & 7.0365 & 0.0937 & 8.967 & -2.94262 & 394.85 & -3.09 \\
$h_{1}$ & 4.5 & 0.6948 & 7.0182 & 0.1259 & 7.8389 & 3.927985 & 409.91 & 0.61 \\
2 & 1.9 & 0.9225 & 7.0114 & 0.0464 & 7.9803 & 2.195014 & 372.72 & -8.52 \\
$h_{2}$ & 2.1 & 1.1999 & 7.0400 & 0.2649 & 8.5048 & -4.23315 & 486.42 & 19.38 \\
8 & 4 & 1.0163 & 7.0217 & 0.2394 & 8.2774 & -1.44618 & 407.03 & -0.09
\end{tabular}




\begin{tabular}{ccccccccc}
$S_{c}$ & 12 & 1.0181 & 7.0211 & 0.0806 & 8.1198 & 0.48533 & 407.58 & 0.04 \\
9 & 8.1 & 1.0155 & 7.0208 & 0.0464 & 8.0827 & 0.94002 & 406.76 & -0.16 \\
$L_{c}$ & 9.9 & 1.0188 & 7.0221 & 0.1942 & 8.2351 & -0.92776 & 407.78 & 0.08 \\
$\mathrm{~W}$ & 25 & 1.1023 & 7.0455 & 0.0777 & 8.2255 & 0.81075 & 387.76 & -4.83 \\
50 & 75 & 0.9231 & 6.9968 & 0.0627 & 7.9826 & -0.81011 & 427.18 & 4.85 \\
0.6 & 0.54 & 1.0189 & 7.0207 & 0.0099 & 8.0495 & 1.346913 & 407.85 & 0.10 \\
$\mathrm{~B}$ & 0.9 & 0.9917 & 7.0312 & 0.4437 & 8.4666 & -3.76498 & 399.24 & -2.01 \\
4 & 2 & 1.1667 & 7.0292 & 0.2108 & 8.4067 & -3.03086 & 449.66 & 10.36 \\
$d_{1}$ & 6 & 0.9927 & 7.0261 & 0.1120 & 8.1308 & 0.350516 & 403.42 & -0.98 \\
4.5 & 4.05 & 1.1264 & 7.0323 & 0.1946 & 8.3533 & -2.3764 & 442.05 & 8.49 \\
$d_{2}$ & 4.95 & 0.9050 & 7.0108 & 0.0450 & 7.9608 & 2.434003 & 37.04 & -90.90 \\
0.02 & 0.01 & 1.0417 & 7.0215 & 0.1200 & 8.1832 & -0.29169 & 407.18 & -0.06 \\
$\alpha$ & 0.03 & 0.9959 & 7.0209 & 0.1211 & 8.1379 & 0.2635 & 407.68 & 0.06 \\
2 & 1 & 1.0237 & 7.0213 & 0.1207 & 8.1657 & -0.07721 & 407.48 & 0.01 \\
$\beta$ & 3 & 1.0146 & 7.0213 & 0.1205 & 8.1564 & 0.036767 & 407.37 & -0.01 \\
0.05 & 0.04 & 1.2431 & 7.8814 & 0.0278 & 9.1523 & -12.1689 & 481.22 & 18.11 \\
$\mathrm{G}$ & 0.06 & 0.8471 & 6.3852 & 0.0049 & 7.2372 & 11.3023 & 353.30 & -13.28 \\
2 & 1 & 4.7889 & 34.392 & 3.7761 & 42.957 & -426.473 & 2118.2 & 419.88 \\
$\mathrm{H}$ & 2.2 & 1.1560 & 6.3660 & 0.2157 & 7.7377 & 5.168272 & 183.83 & -54.88 \\
\hline
\end{tabular}

Note: Because $\mathrm{B}, L_{c}, h_{2}, h_{1}$ and $\mathrm{g}$ are found to be unreasonable when $\mp 50 \%$ changes are made therefore sensitivity analysis is performed by changing $\mp 5 \%$ to $\mp 20 \%$ at a time.

\section{NUMERICAL EXAMPLES}

To analyse the model, we consider the demand rate function to be $\mathrm{f}(\mathrm{t})=\mathrm{A} e^{b t}$, where $\mathrm{A}$ is the initial demand rate at $\mathrm{t}=0$ and $\mathrm{b}$ is the shape parameter .If $b=0$, demand remain constant with time, while $b>0$ implies that demand increases exponentially with time. In view of Tailor series expansion, for finite values of $t$, small value of $b$ would be good representations of the linear, quadratic etc. polynomials of degree depending upon the magnitudes of $b$ and $u$.We consider two different parameter sets corresponding to the situations where (i) $\boldsymbol{\Delta}_{\mathbf{1}}-$-system is optimal

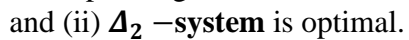

Example-1: Consider the following set of values of parameters: $A=30 . b=4.5, C_{o}=500, u=0.5, h_{1}=3.0, h_{2}=$ 2.0, $W=50, S_{c}=0.15, L_{c}=0.20, d_{1}=4.0, d_{2}=4.5, \alpha=$ $0.02, \beta=2, g=0.05, h=2, B=0.6$, The optimal results obtained from the $\boldsymbol{\Delta}_{\mathbf{1}}$-system has shown in Table-1. For these parameters of value the RW has optimal solution in subcase-1 and OW has optimal value in subcase-2.

\section{Example2:}

Next we increase the value of $S_{c}$ and $L_{c}$ much higher than .Let us take $S_{c}=8$ and $L_{c}=9$,Keeping the other set of values of parameters same as in example -1 .For the $\boldsymbol{\Delta}_{\mathbf{1}}$-system the optimal values obtained are shown in Table -2. In subcase$1\left(R_{s 1}=2448>W\right)$ is much higher than W.We must check for $\boldsymbol{\Delta}_{\mathbf{2}}$-system and found that the total cost in three cases of $\boldsymbol{\Delta}_{\mathbf{2}}$ - system are less expensive than in subcase-1 of RW and OW of $\Delta_{1}-$ system.

\section{Numerical results}

We conclude from the above numerical result as follows:

1. From Table-1, when all the given conditions and constraints are satisfied, the optimal solution is obtained. In this example the minimal present value of total relevant inventory cost per unit time in an appropriate unit for subcase -1 is 172.34 and 192.99 for subcase -2 , for RW-Case and 864.39 for subcase- 1 and 29.74 for subcase-2 for OW-Case. From the above result we see that in subcase- $2, \mathrm{OW}$ - system is less expensive while in case -1 , RW system is less expensive.
2. From Table-2, when all the given conditions and constraints are satisfied, the optimal solution is obtained. In this example the minimal present value of total relevant inventory cost per unit time in an appropriate unit is less expensive for each case for $\boldsymbol{\Delta}_{\mathbf{2}}$ - system when there is bulk amount of inventory purchased as compared to subcase-1 of RW and OW of $\Delta_{1}$ - system. In subcase-2 of RW $\Delta_{1}$ - system is less expensive when capacity of ware house is taken to be unlimited and in case limited capacity i.e. below 50 units of inventory subcase- 2 of OW is very less expensive as compared to $\boldsymbol{\Delta}_{\mathbf{2}}-\mathbf{s y s t e m}$.

3. The convexity of graphs shown in Figure-8 for each case of $\boldsymbol{\Delta}_{\mathbf{1}}$ - system and in Figure- $\mathbf{9}$ for each cases of $\boldsymbol{\Delta}_{2}$-system shows that there are points where inventory system has minimal cost depending upon the capacity of ware-houses and cycle length and that point is unique.

4. The parabolic graphs shown in Figure-10 for $\boldsymbol{\Delta}_{\mathbf{1}}$ system and in Figure-11 for $\boldsymbol{\Delta}_{\mathbf{2}}$ - system shows that inventory cost is directly proportional to the cycle length and has a minimal point where the cost function is minimal.

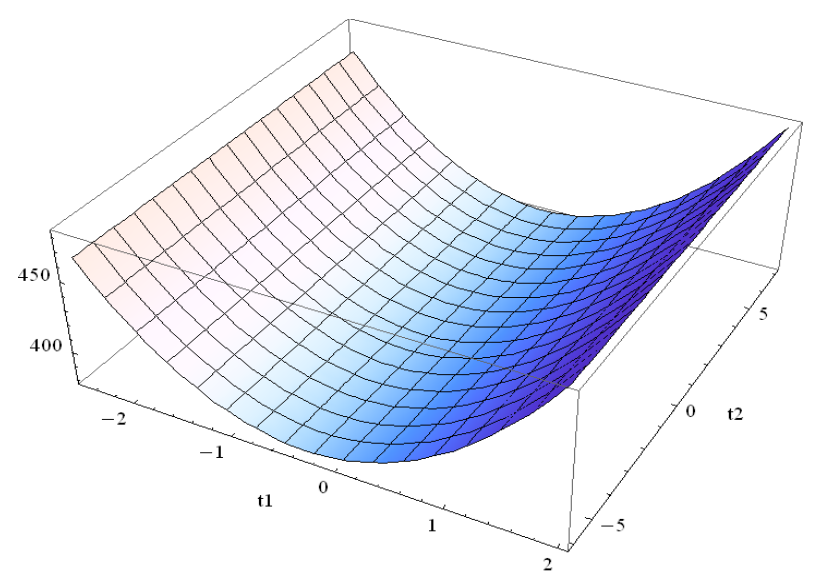

Csae-1 


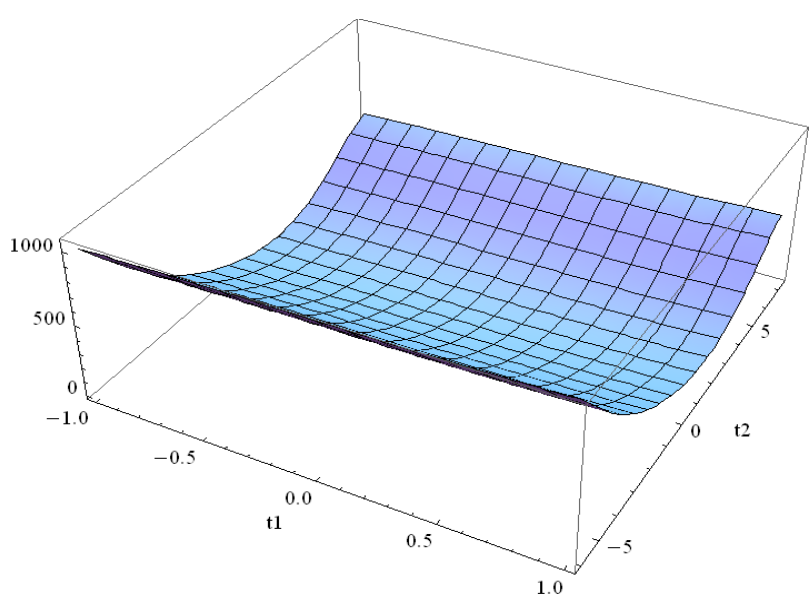

Case-2

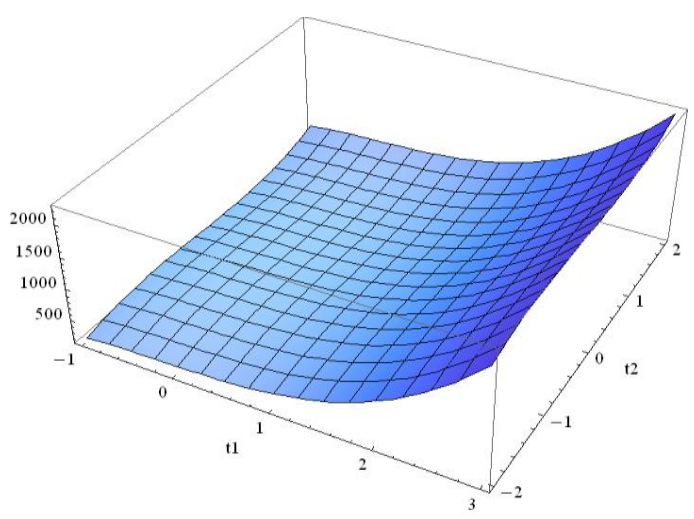

Case-3

Figure-9: Graphical representation of convexity for $\Delta_{2}-$ system

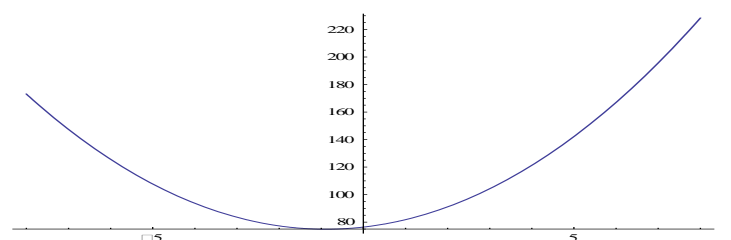

RW-1

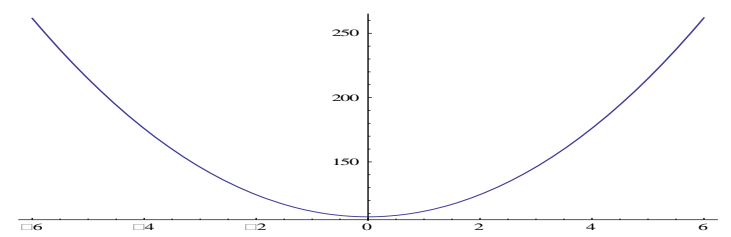

RW-1

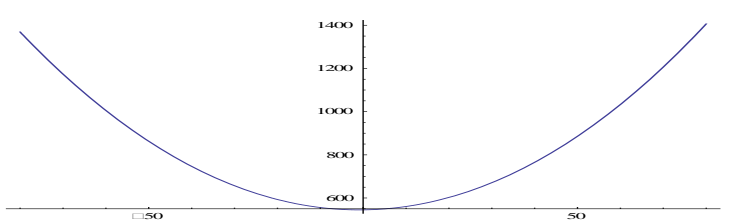

OW -1

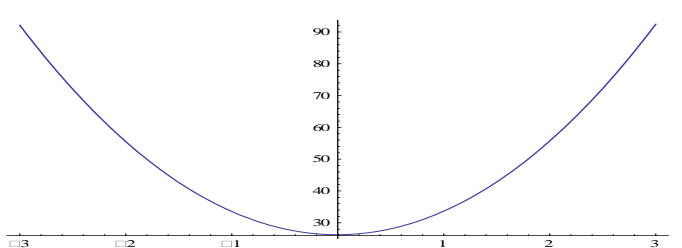

OW -2

Figure-10: Graph presenting Cycle length verses Inventory cost for $\Delta_{1}$-system

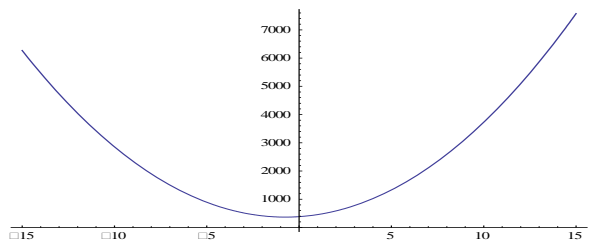

Case-1

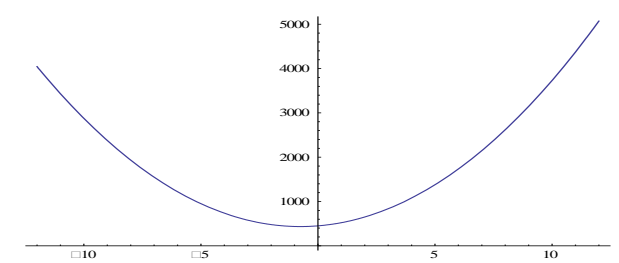

Csae-2

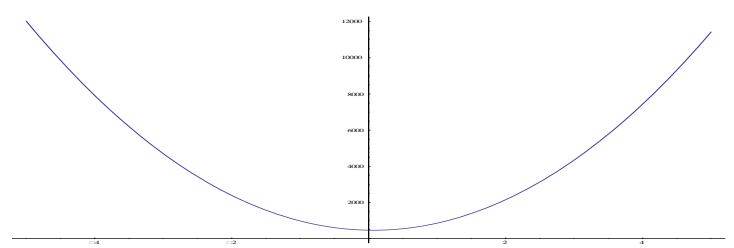

Case-3

Figure-11: Graph presenting Cycle length verses Inventory cost for $\Delta_{2}-$ system

\subsection{Sensitivity Analysis}

It is clear from table -3 that the following phenomenon can be obtained.

- As the value of A,b,c and $u$ and holding cost in OW increases, the total present worth relevant inventory cost per unit of time increases and is highly sensitive to these parameters.

- Total present worth relevant inventory cost per unit of time increases as $h_{2}, s_{c}, L_{c}, \mathrm{~W}$ increases and is moderately sensitive to these parameters change.

- Total present worth relevant inventory cost per unit of time decreases as $d_{1}, d_{2}, \mathrm{~B}, \mathrm{~g}$ increases and slightly sensitive to $\mathrm{B}$, moderately sensitive to $d_{1}$ and highly sensitive to $\mathrm{g}$ and $d_{2}$ but consistent with change of parameters $\alpha$ and $\beta$.

- Total present worth relevant inventory cost per unit of time is very highly sensitive to the shape parameter $h$ and increases as $\mathrm{h}$ increases. 


\section{CONCLUSION}

In this paper, a deterministic inventory model is presented to determine the optimal replacement cycle for two warehouse inventory problem under varying rate of deterioration and partial backlogging .The model assumes that the capacity of distributors' warehouse is limited. The optimization technique is used to derive the optimum replenishment policy i.e. to minimize the total relevant cost of the inventory system. A numerical example is presented to illustrate the model. When there is single ware house is assumed in the inventory system then the total relevant cost per unit time of the system are higher than the two warehouse model. This model is most useful for the instant deteriorating items under Weibull distribution deterioration rate as inventory cost depending on demand is indirectly proportional to demand. Further this paper can be enriched by incorporating other types of time dependent demand and another extension of this model may be for a bulk release pattern with combination of other realistic factors. In practice, now days pricing and advertising also have effect on the demand rate and must be taken into consideration.

\section{REFERENCES}

[1] Sarma,K.V.S.,1983. A deterministic inventory model for deteriorating items with two level of storage and an optimum release rule,Opsearch $20,175-180$.

[2] Murdeshwar,T.A., Sathe, Y,S.1985. Some aspects of lot size model with two level of storage, Opsearch22,255262 .

[3] Dave U. 1988. On the EOQ models with two level of storage.Opsearch25, 190-196.

[4] SarmaK.V.S.,1987. A deterministic order level inventory model for deteriorating items with two storage facilities,Eur.J. Oper.Res.29, 70-73.

[5] Pakala,T.P.M.,ArcharyK.K.,1992a. Discrete time inventory model for deteriorating items with twowarehouses, Opsearch 29, 90-103.

[6] Pakala,T.P.M.,Archary K.K.,1992b.Archary,A deterministic inventory model for deteriorating items with two warehouses and finite replenishment rate, Eur.J. Oper.Res.57 ,71-76.

[7] Yang H.L., 2004. Two warehouse inventory models for deteriorating items with shortages under inflation, Eur.J. Oper.Res.157, 344-356.

[8] Dye,C.Y.,Ouyang,L.Y.,Hsieh,T.P.,2007.deterministicijnve ntory model for deteriorating items with capacity constraints and time proportional backlogging rate, Eur.J. Oper.Res.178 (3), 789-807.
[9] Donaldson,W.A.,1977. Inventory replenishment policy for a linear trend in demand: An analytical solution, Operational Research Quarterly28, 663-670.

[10] Goswami, A.,Chaudhuri,K.S.,1992.An EOQ model for items with two levels of storage for a linear trend in demand, Journal of the Operational Research Society $43,157-167$.

[11] Bhunia,A.K.,Maiti,M.,1994.A two warehouse Inventory model for a linear trend in demand, Opsearch 31, 318-329.

[12] Bhunia,A.K.,Maiti, M.,1998.A two warehouse inventory model for deteriorating items with linear trend in demand and shortages, Journal of the Operational Research Society 49,287-292

[13] Banarjee,S.,Agrawal,S.,2008.Two warehouse inventory model for the items with three parameter Weibull distribution deterioration, linear trend in demand and shortages, International Transaction in Operational Research 15,755-775.

[14] Ritchie,E.,1980. Practical inventory replenishment policies for a linear trend in demand followed by a period of steady demand ,Journal of Operational Research Society 31(7),605-613

[15] Wu,K.S.,2001. An EOQ inventory model for items with Weibull distribution deterioration, Ramp type demand rate and partial backlogging, Production Planning and Control $12,787-793$

[16] Giri,B.C.,Jalan,A.K.Chaudhari,K.S.2003. Economicorder quantity model with Weibull distribution deterioration, shortages and ramp type demand, International Journal of System Science 34, 237-243.

[17] Deng,P.S.,Lin,R.H.J., Chu,P.,2007. A note on the inventory models for deteriorating items with ramp type demand rate, Eur.J. Oper.Res.178, 112-120.

[18] Skouri,K.,Konstantaras,I.,Papachristos,S.Ganas,I.,2009.Inv entory models with ramp type demand rate ,partial backlogging and Weibull deterioration rate, Eur.J. Oper.Res.192, 79-92.

[19] Agrawal,Swati,Banarjee,Snigdha,2011.Two warehouse inventory model with ramp type demand and partially backlogged shortages, International journal of Systems Science 42(7), 1115-1126.

[20] Agrawal,Swati, Banarjee,Snigdha,2013. Inventory model with deteriorating items, ramp type demand and partially backlogged shortages for a two warehouse system, Applied Mathematical Modelling 37, 8912-8929. 